\title{
Robot-assisted surgeries in oral and maxillofacial area: a narrative review on the present, advantages and its future
}

\author{
Hyounmin Kim^, Sung-uk Cho^, Dongwook Kim^ \\ Department of Oral \& Maxillofacial Surgery, Yonsei University College of Dentistry, Seoul, Korea \\ Contributions: (I) Conception and design: D Kim; (II) Administrative support: None; (III) Provision of study materials or patients: D Kim; (IV) \\ Collection and assembly of data: H Kim, S Cho; (V) Data analysis and interpretation: H Kim, S Cho; (VI) Manuscript writing: All authors; (VII) \\ Final approval of manuscript: All authors. \\ Correspondence to: Dongwook Kim, MD, DDS, PhD. Assistant Professor, Department of Oral \& Maxillofacial Surgery, Yonsei University College of \\ Dentistry, 50-1 Yonsei-ro, Seodaemun-gu, Seoul, 03722, Korea. Email: DWKIMOMFS@yuhs.ac.
}

\begin{abstract}
Background and Objective: With the accumulation of advances in minimally invasive surgery in the entire body area, robot-assisted surgeries have become very common in operating rooms, despite of their short history. Thus, advances in robotic surgery are accelerating rapidly, particularly with respect to the maxillofacial region. In this regard, researchers reviewed the literatures using the keywords given below, including systematic meta-analysis. To survey the advantages, future prospects, and cases using robotic systems in oromaxillofacial surgery.

Methods: The report follows the format of the "narrative review" and reviewed literatures extracted from the PubMed database since 1980 when 'Robotic surgical procedures', 'neck dissection' and 'oral surgery' were searched.

Key Content and Findings: It reveals the history and current use of robots in the head and neck area, and introduces the advantages and limitations of robots over conventional methods. Mainly describes the neck dissection and reconstruction surgery in the oral and maxillofacial areas.

Conclusions: Robotic surgery in the oral and maxillofacial region allows the incision to hide the scar by making the incision line far from the surgical field, resulting in fewer intra-operative and post-operative complications, such as amount of drainage or hospital days. Furthermore, recent studies show similar or superior results in terms of oncologic safety of robot assisted surgeries compared to conventional surgeries. Robotic surgery is likely to extend throughout the oral and maxillofacial region once it becomes capable of manipulating bone such as in osteotomies, particularly as robotic systems become smaller. When combined with artificial intelligence technology, the surgical robot will become more useful and powerful in relieving human suffering.
\end{abstract}

Keywords: Robotic surgical procedures; neck dissection; oral surgery

Received: 07 March 2021; Accepted: 09 September 2021; Published: 10 June 2022.

doi: $10.21037 /$ fomm-21-25

View this article at: https://dx.doi.org/10.21037/fomm-21-25

\section{Introduction}

Efforts have continued to be made toward minimally invasive surgery (MIS), with head and neck surgery requiring incisions which will leave long visible scars to be used to approach the lesion. However, due to the difficulty in ligation of neurovascular structures, visualization of surgical fields, and proximity of anatomical critical structures, only recently have there been significant advances in minimally invasive techniques as applied in oral and maxillofacial surgery $(1,2)$.

A series of attempts to achieve MIS were made using

\footnotetext{
^ ORCID: Hyounmin Kim, 0000-0002-1900-4744; Sung-uk Cho, 0000-0001-7424-4786; Dongwook Kim, 0000-0001-6167-6475.
} 
Table 1 The search strategy summary

\begin{tabular}{ll}
\hline Items & Specification \\
\hline Date of search & January 4th to February 3rd, 2021 \\
Databases and other sources searched & MEDLINE (PubMed) \\
Search terms used & "Robotic surgical procedures", "robotic surgery", "neck dissection", "oral surgery" \\
Any additional considerations, if applicable & $\begin{array}{l}\text { This paper is written in the form of a narrative review, which known as an } \\
\text { unsystematic review and provides comprehensive narrative syntheses, regarding the } \\
\text { information reported so far and our experience. Therefore, we present this article in } \\
\text { accordance with the Narrative Review reporting checklist }\end{array}$ \\
\hline
\end{tabular}

endoscopy, but was not so easy to operate (3). Given that robotic surgical systems can address these shortcomings, the use of robots in head \& neck and maxillofacial surgery has recently become more common.

In this regard, we have borrowed the form of a narrative review (4), which known as an unsystematic review and provides comprehensive narrative syntheses, regarding the information reported so far and our experience. Therefore, we present this article in accordance with the Narrative Review reporting checklist (available at https://fomm. amegroups.com/article/view/10.21037/fomm-21-10/rc).

\section{Methods}

This paper is written in the form of unsystematic narrative review that focuses on inter-literature arbitration and comparison. Research of articles was conducted using the keyword including "Robotic Surgical Procedures", "Neck dissection", "Oral surgery" from the 1980s onwards on the PubMed database (Table 1).

\section{Discussion}

First of all, it seems that the explanation for the narrative review should be added first (4). Narrative reviews are also known as unsystematic narrative reviews, which may provide critique of the literatures being reviewed, but are not essential (5). This format is close to an educational article to keep clinicians up to date with low-scientific level, and is far from the articles that should derive objective results or design specific studies (6-8). Therefore, we will elaborate on the latest views and our experiences in the form of a narrative review.

\section{History}

The use of robots in the medical field started with the use of needles in brain biopsies in $1985(2,9)$. Introduced in 1994, the first generation robotic system AESOP (Automated Endoscopic System for Optimal Positioning) was often used in cardiac, urologic, and gynecologic surgeries although it suffered several deficiencies (10). The second generation ZEUS Robotic Surgical System was introduced in 2001 (11). If Zeus was for surgeons who were accustomed to laparoscope, the third generation da Vinci system (Intuitive Surgical Inc., Sunnyvale, CA, USA) lent itself more to open surgery, being first used for surgery in the head and neck region (cf. excision of a vallecular cyst in 2005) and receiving FDA approval in 2009 for use on T1 and T2 cancers (12).

Da Vinci, which remains the most recent surgical system, has now undergone several developments. The Da Vinci single-port (SP) platform enables a less invasive approach than multiple ports (13).

\section{Advantages}

\section{Cosmesis}

Unlike conventional approaches, which require $10-15 \mathrm{~cm}$ of transcervical lip split incision, robotic surgery using trans-axillary or retro-auricular approaches naturally yield better aesthetic results. Studies by Ji and Lee evaluating postoperative cosmesis of robotic surgery in the head and neck region using a scoring system noted superior results over conventional approaches $(14,15)$.

\section{Complications}

By enabling a transoral or retroauricular approach even in cases requiring the transcervical approach, or mandibulotomy with lip split, robotic surgery can reduce functional damage and decrease blood loss based on criteria such as the number of transfusions or mean drain stay (16). The length of hospital stay, chyle leak, hematoma, nerve 

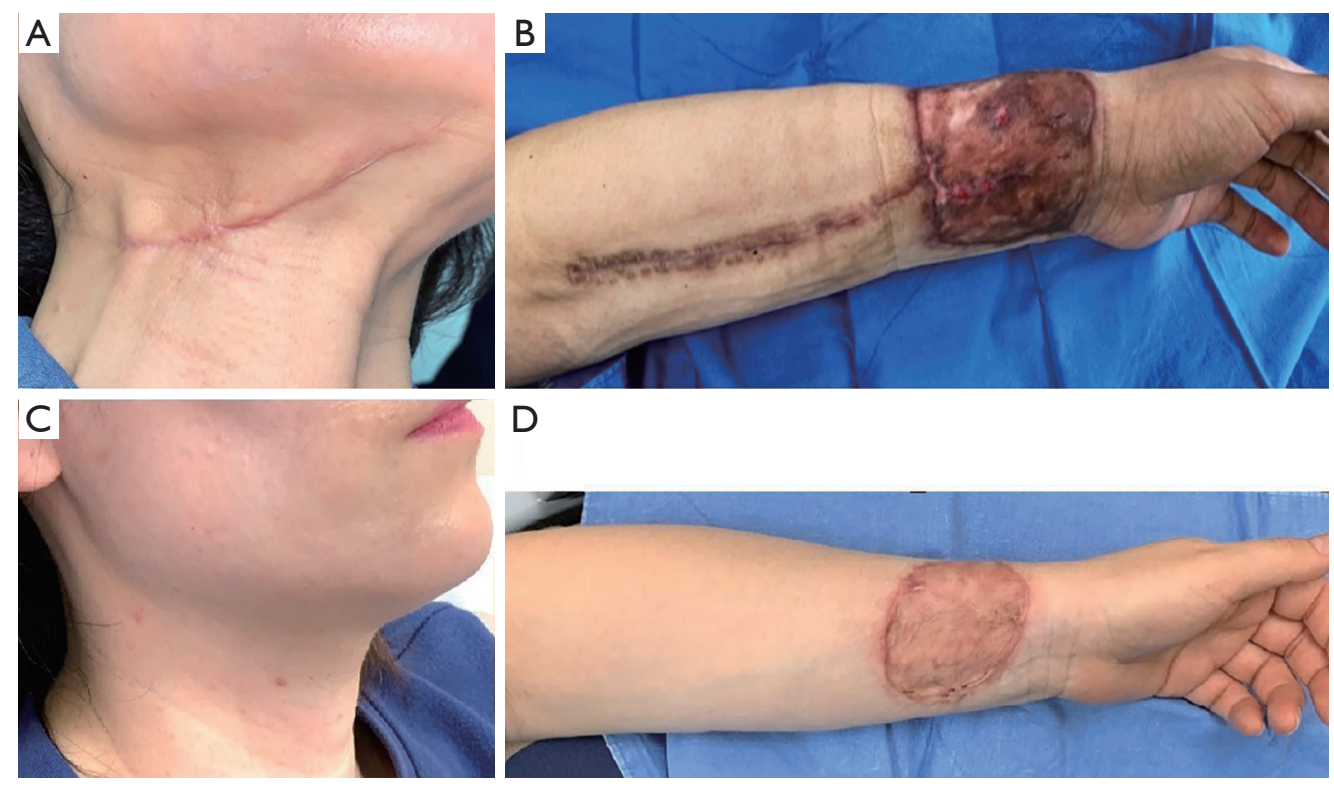

D

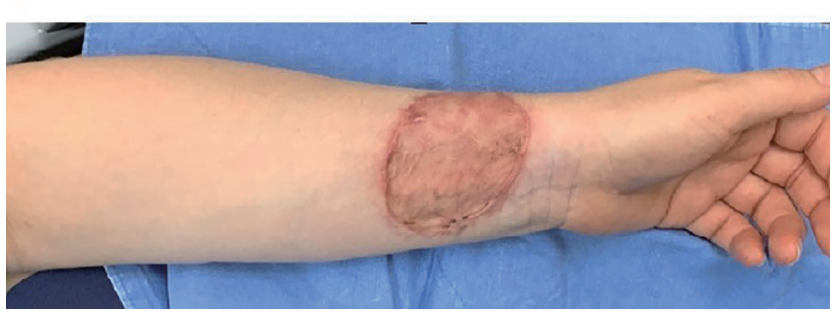

Figure 1 Comparison of postoperative scars. (A,B) Postoperative photograph of a patient who underwent neck dissection and forearm free flap reconstruction for tongue cancer. Note the visible scars. (C,D) Postoperative photograph of a patient who underwent robot-assisted neck dissection and robot-assisted forearm free flap harvesting. The neck scar is undetectable, and the forearm scar is restricted to the flap region, with no long incision scar following pedicle harvesting.

weakness, seroma, wound infections and wound drainage have been evaluated in order to compare the postoperative course of robot assisted surgeries with conventional ones. According to a meta-analysis by Sukato et al. (17), there was no difference in the morbidity of local complications between robotic and conventional groups, nor was there a statistically significant difference in length of hospital stay. In addition, the incision line distant from the surgical site has clear advantages during radiotherapy (Figure 1).

\section{Minimal required medical staff}

Only one surgeon and one or two nurses are required for surgeries which would normally require at least three surgeons and two nurses (2).

\section{Oncologic safety}

Since robotic surgery is relatively new and prospective randomized control trials are lacking (12), oncologic safety has not been fully evaluated. The concept of "lymph node yield" has emerged as a factor for evaluating the oncologic safety of robotic surgery because it becomes an important prognostic factor for survival within a limited follow-up time (18).
In addition to the lymph node yield, the local recurrence rate also shows no statistically significant difference between the two groups in the oromaxillofacial region as well as in the case of neck dissection accompanying thyroidectomy (17).

\section{Limitations}

\section{Lack of haptic feedback}

It is impossible to feel the resistance, strength, pulse of the tissues directly through the currently available surgical robots. Even though visual cues can compensate for the lack of haptic feedback, multiple capsule breakages have been reported in the case of capsulated tumor such as pleomorphic adenomas due to the lack of haptic feedback during grasping and dissecting (11). Future developments will likely provide haptic feedback to reduce the neoplasm rupture and operation time, while a number of surgical experiences may enable such improvement even without haptic feedback (19).

\section{Complexity \& cost}

The docking process and surgery itself requires a specific amount of time and training to warrant fluency (20). 


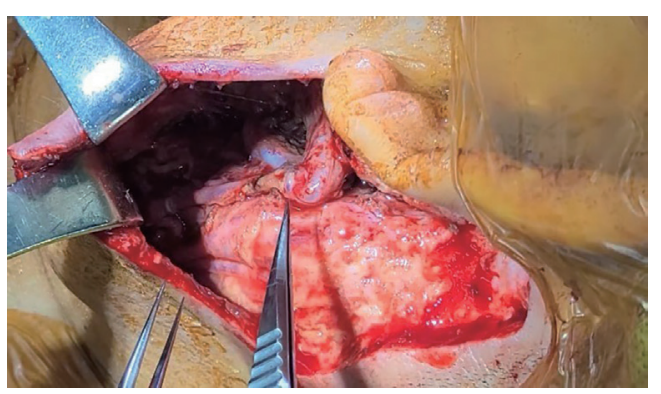

Figure 2 The vision of the vascular anastomosis is secured through facelift incisions.

Structured training programs are provided to achieve such expertise. Thus, robotic surgery is not covered by the national health insurance system, patients have to pay considerable costs. Nevertheless, insurance coverage differs among countries for such a procedure, which is usually more costly than conventional surgeries.

Other than this, tongue edema due to similar or slightly longer operation times compared to conventional methods (21), difficulty of access due to limit to the space between the skin and the subplatysmal space in the head and neck $(22,23)$.

\section{Clinical applications}

\section{Removal of a tumor}

Tumors in the head and neck are often resected, including structures essential for speaking and swallowing, such as pharynx and larynx. However, we can see from a number of examples that robots approach normal tissues with minimal invasion, thus preserving pronunciation and swallowing function as much as possible $(12,24,25)$. Similarly, several studies have reported significantly better functional recovery using robots as measured by the following criteria: proportion of negative operative margin, recurrence-free \& disease-free survival, overall survival, hemorrhage risk, and gastrotomy or tracheo tube insertion rate (26-30). The quality of life of patients undergoing transoral robotic surgery (TORS) decreased significantly for 3-6 months after surgery, then returned to preoperative condition a year later (31). Furthermore, Park et al. have shown that robotic surgery results in significantly less postoperative pain and anxiety as well as faster restoration of appetite (29).

Removing a tumor from parapharyngeal space requires access through the neck, often combined with mandibulotomy, resulting in noticeable scars and, in some cases, mandibulotomy-related complications. TORS has shown advantages over traditional methods in terms of the incidence of complications and postoperative bleeding $(21,22)$. Lee et al. showed that the TORS group had shorter operation times, more rapid recovery of swallowing, and shorter hospital stays than the conventional group (32). Although the transcervical approach is inevitably required in the case of, for example, submandibular gland excisions, an "invisible scar" is achievable using a retroauricular approach or modified face lift incision. In addition to this aesthetic benefit, robotic surgery offers a technical advantage: whereas open surgeries require an inconvenient change of instruments to use a neurostimulator, a robot with an attached neurostimulator emits a warning sound when the robot arm touches a nerve.

\section{Neck dissection}

The first neck dissection using a robot, through the transaxillary approach, was reported by Kang et al. (33). Kang et al. also reported that long, visible scars and decreased muscle performance caused by dissection to deep areas were preventable. However, due to the difficulty of dissecting Levels I and IIB with transaxillary approach, Lee $e t$ al. developed and reported the retroauricular, or face-lift, approach (34). Though robot-assisted neck dissection obviously takes longer than open surgery, intra-operative bleeding, nodal recurrence, postoperative drainage and hospital stay are similar to those of open surgeries, and patients are quite satisfied with postoperative aesthetics $(16,34)$.

\section{Cleft palate}

Robotic surgery to cleft lip and palate is still in its early stages. Nadjmi reported that muscle sling reconstruction took an average of 9.5 months $(n=10)$, much longer than with conventional surgeries, but with significantly shorter hospital stay and functional recovery (35). Nadjmi attributes these results to the precision of robotic dissection, which reduces damage to vascularization and innervation of muscles.

\section{Microvascular reconstruction using free flaps}

Even with retroauricular approaches or partial extension to the preauricular incisions, large flaps such as fibular osteocutaneous flaps can be positioned and done with anastomoses (Figure 2), resulting in more aesthetic results 


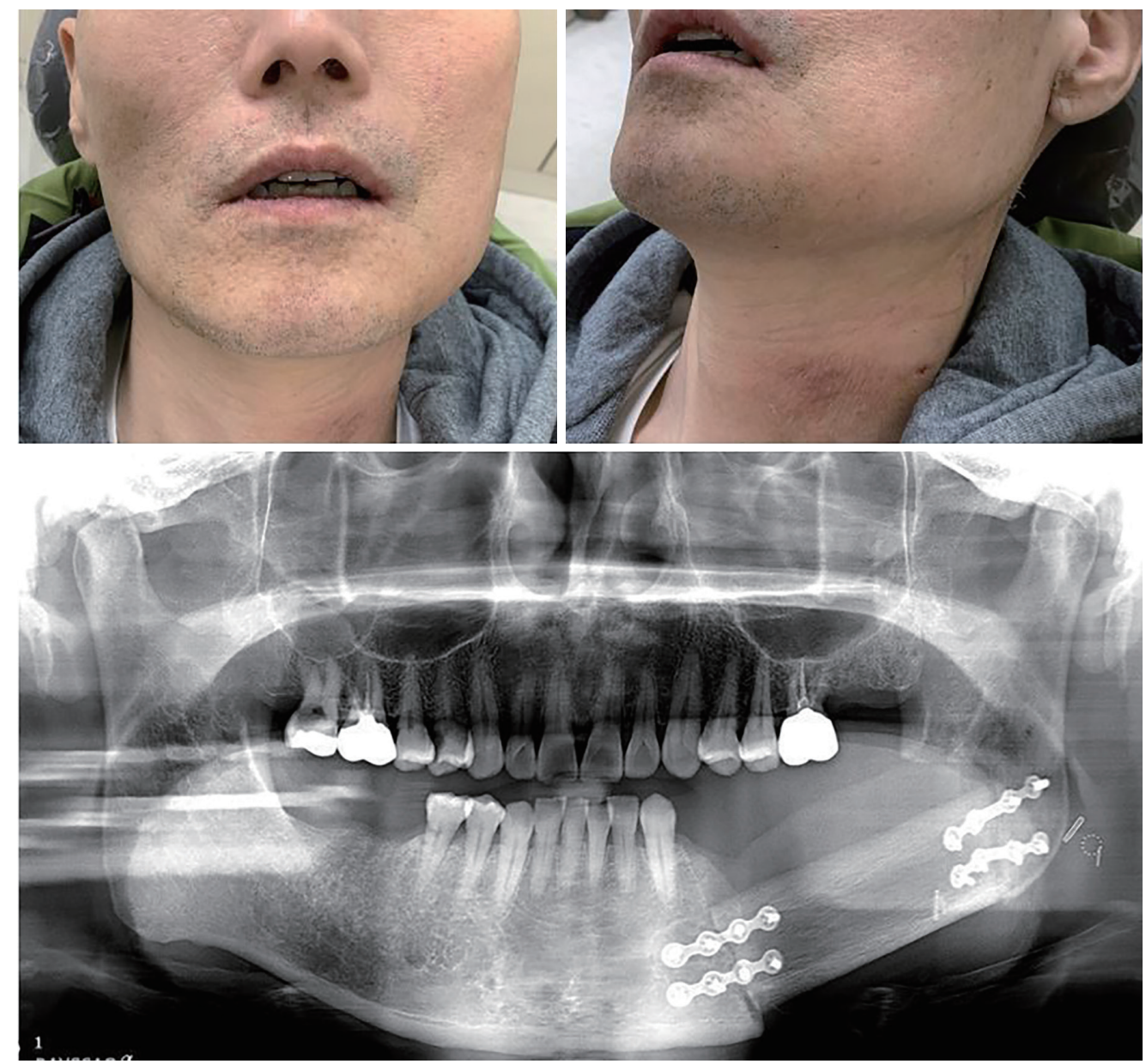

Figure 3 Postoperative photographs of a patient who underwent selective neck dissection (levels I, II, III), segmental resection of mandible and reconstruction with fibula osteocutaneous free flap via intraoral \& retroarticular approach. The surgery has left no visible traces. This image is published with the patient's consent.

than with conventional surgical procedures that require transcervical approaches (Figure 3).

Scar reduction is imperative, not only in flap insetting, but also in flap harvesting, and is feasible with robots $(36,37)$. Using robots to harvest radial forearm free flaps can provide superior postoperative outcome in terms of both aesthetics and complications (Figure 1). Robot-assisted maxillofacial surgery with free flap reconstruction is reported to yield no statistically significant difference compared to conventional approaches in the morbidity of postop infection, drain time and ICU or hospital stay (16).

\section{Conclusions \& perspectives}

Currently the robot cannot perform surgeries involving manipulation of the bone, such as osteotomy or ostectomy. Advances enabling osteotomies may lead to the development and widespread use of robots in the field of craniomaxillofacial surgeries, which frequently involve manipulation of bones. Flexibility and miniaturization of multiports is also needed.

In addition to technical considerations, it is expected that artificial intelligence (AI) and imaging technology will be commonly incorporated into robotic surgical systems, further enhancing their utility.

Image-guided surgeries, performed after injecting ICG dye into blood vessels, have been used to delineate the cancer margin in urology, hepatobiliary, and colorectal surgery, as well as to explore sentinel nodes; there are also reports of robots being used in monitoring the flap pedicle 
(38-40). Da Vinci's camera has a built-in Near Infrared (NIR) system which can be activated simply by finger trigger.

We expect improved interaction between robot and environment for simple surgical tasks such as suturing; recognizing the surgeon's gaze, hand gestures, or voice; and making the robot do the work of a nurse, such as tool changes. Furthermore, visual model-based reinforcement learning may lead to robotic execution of complex tasks such as surgical procedures (41). Finally, by utilizing a large database of surgical procedures, the deep learning process will not only reduce unexpected situations during surgery, but also avoid dangerous situations within closed spaces (e.g., arthroplasty) by establishing safe boundaries (2).

\section{Acknowledgments}

The authors thank Eph Tunkle for his excellent English correction.

Funding: None.

\section{Footnote}

Provenance and Peer Review: This article was commissioned by the Guest Editor (Sung-Kiang Chuang) for the series "Clinical Outcomes and Innovations in Oral and Maxillofacial Surgery" published in Frontiers of Oral and Maxillofacial Medicine. The article has undergone external peer review.

Reporting Checklist: The authors have completed the Narrative Review reporting checklist. Available at https://fomm. amegroups.com/article/view/10.21037/fomm-21-10/rc

Conflicts of Interest: All authors have completed the ICMJE uniform disclosure form (available at https://fomm. amegroups.com/article/view/10.21037/fomm-21-10/coif). The series "Clinical Outcomes and Innovations in Oral and Maxillofacial Surgery" was commissioned by the editorial office without any funding or sponsorship. The authors have no other conflicts of interest to declare.

Ethical Statement: The authors are accountable for all aspects of the work in ensuring that questions related to the accuracy or integrity of any part of the work are appropriately investigated and resolved.

Open Access Statement: This is an Open Access article distributed in accordance with the Creative Commons
Attribution-NonCommercial-NoDerivs 4.0 International License (CC BY-NC-ND 4.0), which permits the noncommercial replication and distribution of the article with the strict proviso that no changes or edits are made and the original work is properly cited (including links to both the formal publication through the relevant DOI and the license). See: https://creativecommons.org/licenses/by-nc-nd/4.0/.

\section{References}

1. Bansal A, Bansal V, Popli G, et al, editors. Robots in Head and Neck Surgery. J Appl Dent Med Sci 2016;2:168-75.

2. Liu HH, Li LJ, Shi B, et al. Robotic surgical systems in maxillofacial surgery: a review. Int J Oral Sci 2017;9:63-73.

3. Steiner W, Ambrosch P, Stengel D, et al. Endoscopic laser surgery of the upper aerodigestive tract. Stuttgart: Thieme, 2000.

4. Green BN, Johnson CD, Adams A. Writing narrative literature reviews for peer-reviewed journals: secrets of the trade. J Chiropr Med 2006;5:101-17.

5. Holroyd-Leduc J, Helewa A, Walker JM. Critical Evaluation of Research in Physical Rehabilitation: Towards Evidence-Based Practice. Philadelphia: WB Saunders Company, 2000.

6. Dunn K. Interpreting the Medical Literature. J Med Libr Assoc 2007;95:91.

7. Hutchison BG. Critical appraisal of review articles. Can Fam Physician 1993;39:1097-102.

8. Oxman AD, Guyatt GH. Guidelines for reading literature reviews. CMAJ 1988;138:697-703.

9. Kwoh YS, Hou J, Jonckheere EA, et al. A robot with improved absolute positioning accuracy for CT guided stereotactic brain surgery. IEEE Trans Biomed Eng 1988;35:153-60.

10. Sackier JM, Wang Y. Robotically assisted laparoscopic surgery. From concept to development. Surg Endosc 1994;8:63-6.

11. Preusche C, Ortmaier T, Hirzinger G. Teleoperation Concepts in Minimal Invasive Surgery. Weingarten, Germany: Proceedings of the 1st IFAC Conference on Telematics Application in Automation and Robotics, 2001.

12. McLeod IK, Melder PC. Da Vinci robot-assisted excision of a vallecular cyst: a case report. Ear Nose Throat J 2005;84:170-2.

13. Joo OY, Song SY, Park HS, et al. Single-port robotassisted prosthetic breast reconstruction with the da Vinci SP Surgical System: first clinical report. Arch Plast Surg 2021;48:194-8. 
14. Ji YB, Song CM, Bang HS, et al. Functional and cosmetic outcomes of robot-assisted neck dissection by a postauricular facelift approach for head and neck cancer. Oral Oncol 2017;70:51-7.

15. Lee J, Kwon IS, Bae EH, et al. Comparative analysis of oncological outcomes and quality of life after robotic versus conventional open thyroidectomy with modified radical neck dissection in patients with papillary thyroid carcinoma and lateral neck node metastases. J Clin Endocrinol Metab 2013;98:2701-8.

16. Lira RB, Chulam TC, de Carvalho GB, et al. Retroauricular endoscopic and robotic versus conventional neck dissection for oral cancer. J Robot Surg 2018;12:117-29.

17. Sukato DC, Ballard DP, Abramowitz JM, et al. Robotic versus conventional neck dissection: A systematic review and meta-analysis. Laryngoscope 2019;129:1587-96.

18. Lemieux A, Kedarisetty S, Raju S, et al. Lymph Node Yield as a Predictor of Survival in Pathologically Node Negative Oral Cavity Carcinoma. Otolaryngol Head Neck Surg 2016;154:465-72.

19. Park YM, Kim DH, Kang MS, et al. Real impact of surgical robotic system for precision surgery of parotidectomy: retroauricular parotidectomy using da Vinci surgical system. Gland Surg 2020;9:183-91.

20. White HN, Frederick J, Zimmerman T, et al. Learning curve for transoral robotic surgery: a 4-year analysis. JAMA Otolaryngol Head Neck Surg 2013;139:564-7.

21. Arian Y. A Review of the Application of Robots in Maxillofacial Surgery. J Oral Health Dent Res 2021;1:1-4.

22. Terris DJ, Haus BM, Gourin CG, et al. Endo-robotic resection of the submandibular gland in a cadaver model. Head Neck 2005;27:946-51.

23. Tae K, Ji YB, Song CM, et al. Robotic selective neck dissection by a postauricular facelift approach: comparison with conventional neck dissection. Otolaryngol Head Neck Surg 2014;150:394-400.

24. O'Malley BW Jr, Weinstein GS, Snyder W, et al. Transoral robotic surgery (TORS) for base of tongue neoplasms. Laryngoscope 2006;116:1465-72.

25. Weinstein GS, O'Malley BW Jr, Snyder W, et al. Transoral robotic surgery: radical tonsillectomy. Arch Otolaryngol Head Neck Surg 2007;133:1220-6.

26. Wei WI, Ho WK. Transoral robotic resection of recurrent nasopharyngeal carcinoma. Laryngoscope 2010;120:2011-4.

27. de Almeida JR, Byrd JK, Wu R, et al. A systematic review of transoral robotic surgery and radiotherapy for early oropharynx cancer: a systematic review. Laryngoscope 2014;124:2096-102.

28. Kelly K, Johnson-Obaseki S, Lumingu J, et al. Oncologic, functional and surgical outcomes of primary Transoral Robotic Surgery for early squamous cell cancer of the oropharynx: a systematic review. Oral Oncol 2014;50:696703.

29. Park YM, Byeon HK, Chung HP, et al. Comparison study of transoral robotic surgery and radical open surgery for hypopharyngeal cancer. Acta Otolaryngol 2013;133:641-8.

30. Hammoudi K, Pinlong E, Kim S, et al. Transoral robotic surgery versus conventional surgery in treatment for squamous cell carcinoma of the upper aerodigestive tract. Head Neck 2015;37:1304-9.

31. Leonhardt FD, Quon H, Abrahão M, et al. Transoral robotic surgery for oropharyngeal carcinoma and its impact on patient-reported quality of life and function. Head Neck 2012;34:146-54.

32. Lee SY, Park YM, Byeon HK, et al. Comparison of oncologic and functional outcomes after transoral robotic lateral oropharyngectomy versus conventional surgery for T1 to T3 tonsillar cancer. Head Neck 2014;36:1138-45.

33. Kang SW, Lee SH, Ryu HR, et al. Initial experience with robot-assisted modified radical neck dissection for the management of thyroid carcinoma with lateral neck node metastasis. Surgery 2010;148:1214-21.

34. Lee HS, Kim WS, Hong HJ, et al. Robot-assisted Supraomohyoid neck dissection via a modified face-lift or retroauricular approach in early-stage cN0 squamous cell carcinoma of the oral cavity: a comparative study with conventional technique. Ann Surg Oncol 2012;19:3871-8.

35. Nadjmi N. Transoral Robotic Cleft Palate Surgery. Cleft Palate Craniofac J 2016;53:326-31.

36. Selber JC, Baumann DP, Holsinger FC. Robotic latissimus dorsi muscle harvest: a case series. Plast Reconstr Surg 2012;129:1305-12.

37. Gundlapalli VS, Ogunleye AA, Scott K, et al. Roboticassisted deep inferior epigastric artery perforator flap abdominal harvest for breast reconstruction: A case report. Microsurgery 2018;38:702-5.

38. Achterberg FB, Sibinga Mulder BG, Meijer RPJ, et al. Real-time surgical margin assessment using ICGfluorescence during laparoscopic and robot-assisted resections of colorectal liver metastases. Ann Transl Med 2020;8:1448.

39. Diana P, Buffi NM, Lughezzani G, et al. The Role of Intraoperative Indocyanine Green in Robot-assisted Partial Nephrectomy: Results from a Large, Multi-institutional 
Series. Eur Urol 2020;78:743-9.

40. Bigdeli AK, Thomas B, Falkner F, et al. The Impact of Indocyanine-Green Fluorescence Angiography on Intraoperative Decision-Making and Postoperative

doi: $10.21037 /$ fomm-21-25

Cite this article as: Kim H, Cho SU, Kim D. Robot-assisted surgeries in oral and maxillofacial area: a narrative review on the present, advantages and its future. Front Oral Maxillofac Med 2022;4:19.
Outcome in Free Flap Surgery. J Reconstr Microsurg 2020;36:556-66.

41. Zhou XY, Guo Y, Shen M, et al. Application of artificial intelligence in surgery. Front Med 2020;14:417-30. 